\title{
The Application of Carbon Footprint Measurement Model in Urban Transportation Planning
}

\author{
Tao Tao ${ }^{1, a^{*}}$, Xiucheng Guo ${ }^{2, b}$ and Xiaohong Jiang ${ }^{3, c}$ \\ ${ }^{1}$ Southeast University, Nanjing, Jiangsu, China \\ ${ }^{2}$ Southeast University, Nanjing, Jiangsu, China \\ ${ }^{3}$ Nanjing Forestry University, Nanjing, Jiangsu, China \\ avtao1989@foxmail.com, bseuguo@163.com, xiaohongjiang2009@gmail.com
}

\begin{abstract}
Keywords: Carbon footprint measurement model; Urban transportation planning; Secondary development of TransCAD

Abstract. The combination of carbon footprint and urban transportation planning is significantly meaningful to the construction of urban low-carbon transportation. This dissertation studies the emission of carbon dioxide and air pollutant such as carbon monoxide, hydrocarbon, nitrogen oxide during the process of transportation, and establishes carbon footprint measurement model to calculate the urban transportation planning projects' emission of carbon dioxide and air pollutant. Then based on the Geographic Information System Developer's Kit (GISDK) development platform and carbon footprint measurement model, secondary development is made in TransCAD to enable the software to calculate the emission of carbon dioxide and air pollutant. The developed software is used to evaluate the carbon footprint of three different urban transportation planning projects of Eco High Tech Island in Nanjing, China and then the most environmentally friendly is chosen to meet the need of developing a low-carbon city.
\end{abstract}

\section{Introduction}

To begin with we provide a brief background on carbon footprint. It is the total amount of greenhouse gas emission caused by an organization, event, product or person during the process of transportation, food production and consumption or other productive lines. It mainly consists of carbon dioxide and air pollutant such as carbon monoxide, hydrocarbon, nitrogen oxide, etc (Wright, L.A. et al. 2011). Energy is consumed and huge amount of carbon emission is generated in the process of vehicles' operation. With the development of transportation in recent years, the carbon emission increases quickly and gradually becomes the main source of the city's carbon emission, which has a negative influence on the global environment (Gomi, K. et al. 2007). Urban transportation planning directly affects the developing direction of transportation industry, including modes, structure and space, which makes great impacts on the carbon footprint of transportation.

Until recently many researchers have shown interest in the field of carbon footprint measurement model's application in urban transportation planning. They have carried out numerous laboratory experiments and field observations to illuminate the darkness of this field. Their findings and suggestions are reviewed below.

Kenworth J. (2003) found that factors such as public transport supply, relationship in land use, quantity and concentration of jobs, transport connection between central city and satellite towns, limitation of the expansion of city boundary had a huge impact on transportation carbon emission. He suggested that developing public transport and non-motorized traffic could decrease the urban energy consumption effectively. McKinnon A.C. \& Piecyk M.I. (2009) proposed that freight carbon emission could be reduced through improving travel mode, vehicle utilization, energy efficiency and energy carbon content. Poudenx P. (2011) concluded that proportion of people using public transport could be increased by means of controlling land use, traffic demand management (TDM), promoting service level and intelligent transportation system (ITS), and then carbon emission would get a reduction. The city of Curitiba in Brazil was taken as an example to support his conclusion. Mensink C. et al. (2000) 
established an urban transport emission model for the Antwerp area. Loo B.P.Y. \& Li L. (2012) estimated the carbon emission of four kinds of passenger transport modes in China based on distance and energy. James C. (2004) designed an urban energy consumption evaluating system and suggested that population density, land use efficiency and urban planning should be used as evaluation indexes to decide whether an urban transportation model was reasonable.

Based on the research results above, we establishes carbon footprint measurement model to calculate the urban transportation planning projects' emission of carbon dioxide and air pollutant. Then based on the GISDK development platform and carbon footprint measurement model, secondary development is made in TransCAD to calculate the emission of carbon dioxide and air pollutant. Then we use the software to evaluate the carbon footprint of three different urban transportation planning projects of Eco High Tech Island in Nanjing, China and choose the most approriate one.

\section{Carbon Footprint Measurement Model}

The carbon footprint measurement model is established to calculate the emission of carbon dioxide and air pollutant such as carbon monoxide, hydrocarbon, nitrogen oxide. Carbon dioxide measurement model is established and based on vehicles fuel consumption, and air pollutant measurement model is primarily based on vehicles emission factors.

Carbon dioxide measurement model. The carbon dioxide emission is mainly caused by vehicles fuel consumption in transportation. We calculate the carbon dioxide emission based on the carbon balance method. This paper supposes that the total amount of carbon, which is produced through fuel consumption, is all emitted outside in the form of carbon dioxide.

The carbon dioxide emission generated during the travel can be calculated with the equation below.

$A=V \times L \times D \times R \times \frac{M\left(\mathrm{CO}_{2}\right)}{M(\mathrm{C})}$

where $A=$ amount of carbon dioxide emission produced through fuel consumption during the travel, $\mathrm{kg} ; V=$ average volume of vehicles fuel consumption per kilometer, $\mathrm{m} 3 / \mathrm{km} ; L=$ vehicles line distance, it is decided by the urban transportation planning, $\mathrm{km} ; D=$ fuel density, $\mathrm{kg} / \mathrm{m} 3$, gaspling is 740 while diesel is 840 on average; $R=$ carbon content of fuel, generally used as $0.8664 ; M\left(\mathrm{CO}_{2}\right)=$ relative molecular mass of carbon dioxide, $44 ; M(C)=$ relative molecular mass of carbon, 12 .

The variable $V$ is related with vehicles' velocity (Nathan, G. et al. 1996), detailed information is shown in Table 1.

Table 1. The relationship between vehicles fuel consumption and velocity.

\begin{tabular}{|c|c|c|c|}
\hline $\begin{array}{c}\text { Velocity } \\
{[\mathrm{km} / \mathrm{h}]}\end{array}$ & $\begin{array}{c}\text { Fuel Consumption } \\
{[\mathrm{L} / \mathrm{km}]}\end{array}$ & $\begin{array}{c}\text { Velocity } \\
{[\mathrm{km} / \mathrm{h}]}\end{array}$ & $\begin{array}{c}\text { Fuel Consumption } \\
{[\mathrm{L} / \mathrm{km}]}\end{array}$ \\
\hline $0 \sim 5$ & 1.40 & $50 \sim 55$ & 0.0889 \\
\hline $5 \sim 10$ & 0.481 & $55 \sim 60$ & 0.0859 \\
\hline $10 \sim 15$ & 0.298 & $60 \sim 65$ & 0.0872 \\
\hline $15 \sim 20$ & 0.220 & $65 \sim 70$ & 0.0893 \\
\hline $20 \sim 25$ & 0.176 & $70 \sim 75$ & 0.0923 \\
\hline $25 \sim 30$ & 0.148 & $75 \sim 80$ & 0.0960 \\
\hline $30 \sim 35$ & 0.129 & $80 \sim 85$ & 0.100 \\
\hline $35 \sim 40$ & 0.115 & $85 \sim 90$ & 0.105 \\
\hline $40 \sim 45$ & 0.104 & $90 \sim 95$ & 0.111 \\
\hline $45 \sim 50$ & 0.0958 & $95 \sim 100$ & 0.117 \\
\hline
\end{tabular}

For different types of vehicles, converted coefficient is used to calculate the corresponding fuel consumption. The specific converted coefficient is listed in Table 2 (Wei, W. et al. 2002). 
Table 2. Fuel consumption converted coefficient for different types of vehicles.

\begin{tabular}{|c|c|}
\hline Vehicle Type & Converted Coefficient \\
\hline Car & 1 \\
\hline Middle-sized Vehicle & 1.37 \\
\hline Heavy Gasoline Vehicle & 2.27 \\
\hline Motorbike & 0.17 \\
\hline Heavy Vehicle & 2.35 \\
\hline Heavy Diesel Vehicle & 3.23 \\
\hline Jeep & 1.37 \\
\hline
\end{tabular}

Air pollutant measurement model. There are mainly three ways for vehicles to emit air pollutant: tail gas, crankcase channeling gas, fuel evaporation. The tail gas consists of $\mathrm{CO}, \mathrm{HC}$ (hydrocarbon), NOX, SO2, particles (including lead, soot), odor; the main ingredient of crankcase channeling gas is $\mathrm{HC}$ (Accounted for about 25\%); fuel evaporation consists of $\mathrm{HC}$ (Accounted for about 20\%). Table 3 lists the air pollutant of three ways (Pingfei, L. et al. 2005).

Table 3. The emission of vehicles' air pollutant.

\begin{tabular}{|c|c|c|c|}
\hline \multirow{2}{*}{ Automobile Parts } & \multicolumn{3}{|c|}{ The Relative Emission (percentage)/\% } \\
\cline { 2 - 4 } & $\mathrm{CO}$ & $\mathrm{HC}$ & $\mathrm{NO}_{\mathrm{X}}$ \\
\hline Exhaust Pipe & $98 \sim 99$ & $55 \sim 65$ & $98 \sim 99$ \\
\hline Crankcase & $1 \sim 2$ & 25 & $1 \sim 2$ \\
\hline Fuel Tank Carburetor & 0 & $10 \sim 20$ & 0 \\
\hline
\end{tabular}

Table 3 shows that tail gas from exhaust pipe is the main ingredient of vehicles emission. It can also be found that $\mathrm{CO}, \mathrm{HC}$ and $\mathrm{NO}_{\mathrm{X}}$ account for the majority of air pollutant. In China, the environmental protection agency takes $\mathrm{CO}, \mathrm{HC}$ and $\mathrm{NO}_{\mathrm{x}}$ as main air pollutant. Therefore, this dissertation studies on the emission factor of the air pollutant which is used to calculate the vehicles emission in the urban transportation planning.

The equation to calculate the emission of air pollutant in transportation is shown below.

$Q_{L i}^{p}=m l_{i} \sum_{j=1}^{k} v_{i j} \times E_{i j}^{p}=v_{i} \times m l_{i} \sum_{j=1}^{k} b_{i j} \times E_{i j}^{p}$

where $Q_{L i}^{\mathrm{p}}=$ emission of pollutant $p$ caused by vehicles in road $i, \mathrm{~g} / \mathrm{h} ; m l_{i}=$ distance of road $i$, $\mathrm{km} ; E_{i j}^{p}=$ emission factor of pollutant $p$, caused by vehicle $j$ in the running condition of road $i$, $\mathrm{g} /(\mathrm{veh} \cdot \mathrm{km})$, its value can be calculated by the MOBILE program (Barth, M. et al. 2011); $V_{i}=$ traffic volume of mixed vehicles in road $i, \mathrm{veh} / \mathrm{h} ; V_{i j}=$ traffic volume of vehicle $j$ in $\mathrm{road} i, \mathrm{veh} / \mathrm{h} ; b_{i j}=$ proportion of vehicle $j$ of mixed vehicles in road $i$, expressed in percentage.

\section{Secondary Development of TransCAD}

The program is developed based on the GISDK development platform of TransCAD software with the programming language of Caliper Script. It is used to calculate the emission of carbon dioxide and air pollutant in the urban transportation planning. The primary structure of the program is shown below.

Data layer. It can read, save, modify the files and emission factors of air pollutant which will be needed in the program.

Operation layer. It is the subject of the program. Functions can be realized through Caliper Script:

a. Get data from data layer and view, modify the data;

b. Input the parameters;

c. Calculate the emission of carbon dioxide and air pollutant;

d. Show the calculation results;

To help the users, the program has many default parameters to choose through dropdown list. Figure 1 shows the operation interfaces of the software. 

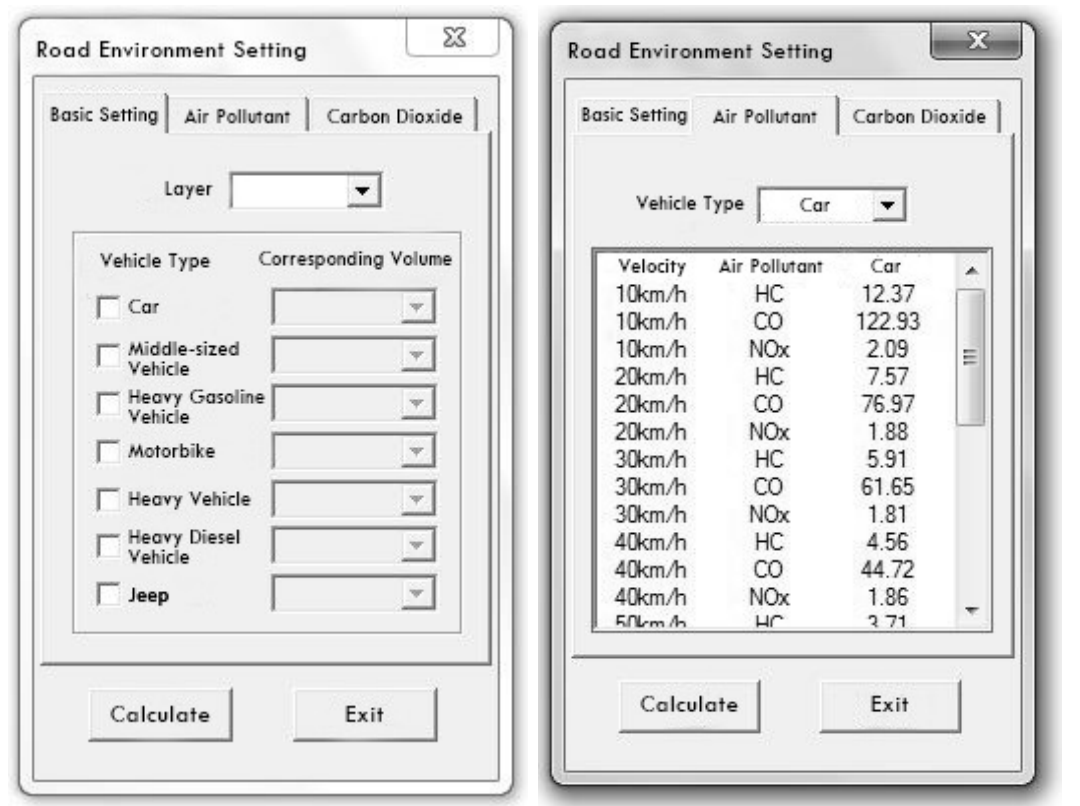

Figure 1. Operation interfaces of operation layer.

Presentation layer. In order to enhance the user experience, push buttons, checkboxes, scroll lists, text items, popdown menus and edit items are used to make the whole program simpler and more visible. There are three taps in the program to set the program and choose the category of carbon footprint to calculate: Basic setting, Carbon dioxide and Air pollutant. The data from data layer can be chosen to be displayed in the scroll lists. The data can be modified by double clicking the item in the list. Figure 2 shows the processing results of the program.

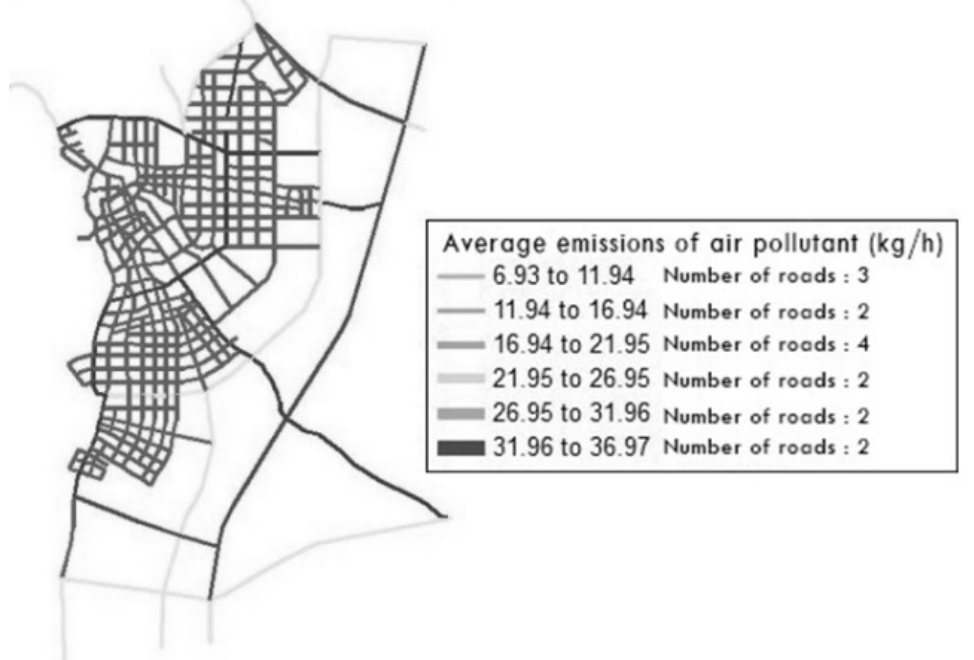

Figure 2. The processing results of the program.

Application in urban transportation planning. The carbon footprint measurement model is applied in the project of Singapore-Nanjing Eco High Tech Island. There are three different urban transportation planning projects, each of which provides the traffic volume, length, number of lanes etc. We use the program discussed above to calculate the emission of carbon dioxide and air pollutant for three different transportation planning projects and compare the results to select a better one.

Table 4 shows the predicted traffic saturability and internal and external structure of travel modes for three projects. 
Table 4. Comparison of three urban traffic planning projects.

\begin{tabular}{|c|c|c|c|c|}
\hline \multicolumn{2}{|c|}{ Urban Traffic Planning } & Scheme 1 & Scheme 2 & Scheme 3 \\
\hline Predicted Traffic Saturability & 1.04 & 0.79 & 0.75 \\
\hline \multirow{4}{*}{$\begin{array}{c}\text { Internal Structure of } \\
\text { Travel Mode }\end{array}$} & Metro & $25 \%$ & $45 \%$ & $48 \%$ \\
\cline { 2 - 5 } & Bus & $20 \%$ & $30 \%$ & $30 \%$ \\
\cline { 2 - 5 } & Car & $25 \%$ & $10 \%$ & $9 \%$ \\
\cline { 2 - 5 } & Taxi & $10 \%$ & $5 \%$ & $3 \%$ \\
\cline { 2 - 5 } & Non-motor vehicle & $15 \%$ & $8 \%$ & $8 \%$ \\
\cline { 2 - 5 } & Walk & $5 \%$ & $2 \%$ & $2 \%$ \\
\hline \multirow{4}{*}{$\begin{array}{c}\text { External Structure of } \\
\text { Travel Modes }\end{array}$} & Total & $100 \%$ & $100 \%$ & $100 \%$ \\
\cline { 2 - 5 } & Bus & $25 \%$ & $40 \%$ & $45 \%$ \\
\cline { 2 - 5 } & Car & $15 \%$ & $25 \%$ & $23 \%$ \\
\cline { 2 - 5 } & Taxi & $25 \%$ & $25 \%$ & $25 \%$ \\
\cline { 2 - 5 } & Non-motor vehicle & $20 \%$ & $8 \%$ & $6 \%$ \\
\cline { 2 - 5 } & Walk & $15 \%$ & $2 \%$ & $1 \%$ \\
\hline
\end{tabular}

\section{Results and Analysis}

We get the distribution of the emission of carbon dioxide and air pollutant (Shown in Table 5).

Table 5. Comparison of the distribution of carbon footprint in three urban traffic planning projects.

\begin{tabular}{|c|c|c|c|}
\hline Schemes & Scheme 1 \\
\hline Distribution of Carbon dioxide emission & & Scheme 2 \\
\hline Total Emission of Carbon Dioxide/ $\mathrm{kg} / \mathrm{h}$ & $23,524,525$ & Scheme 3 \\
\hline Distribution of Air Pollutant Emission & & & \\
\hline Total Emission of Air Pollutant/ $\mathrm{kg} / \mathrm{h}$ & $3,201,701$ & $1,952,793$ & $1,783,572$ \\
\hline
\end{tabular}

In these three urban traffic planning projects, emission of scheme 1 is the most one, and scheme 3 is the fewest one. It is no doubt that scheme 3 is much better than the other two in environmental protection and people's health. However, for better environment, scheme 3 sacrifices some traffic volume, which wastes much traffic resource. In scheme 2, the total emission of carbon footprint is relatively low and the traffic volume is enough to keep the vehicles. So scheme 2 is the best unban traffic planning in overall consideration.

The results also prove that the carbon footprint measurement model is really useful in actual operation.

\section{References}

[1] Barth, M., Malcolm, C., Younglove, T., \& Hill, N. 2001. Recent validation efforts for a comprehensive modal emissions model. Transportation Research Record: 1323. 
[2] Gomi, K., Shimada, K., Matsuoka, Y., \& Naito, M. 2007. Scenario study for a regional low-carbon society. Sustainability Science 2(1): 121131.

[3] Hanwen, Y. \& Mulinazzi, T.E. 2004. Methods and models for site impact traffic evaluation. Urban Transport of China.

[4] James, C. 2004. Methods and Models for Site Impact Traffic Evaluation. Urban Transport 2(1): 5662.

[5] Kenworth, J. 2003. Transport energy use and greenhouse gases in urban passenger transport systems: a study of 84 global cities. Reports for Community Partners.

[6] Loo, B.P.Y. \& Li, L. 2012. Carbon dioxide emissions from passenger transport in china since 1949: implications for developing sustainable transport. Energy Policy 50(6): 464-476.

[7] McKinnon, A.C. \& Piecyk, M.I. 2009. Measurement of CO2 emissions from road freight transport: a review of uk experience. General Information 37(10): 3733-3742.

[8] Mensink, C., Vlieger, I.D. \& Nys, J. 2000. An urban transport emission model for the antwerp area. Atmospheric Environment 34(27): 45954602(8).

[9] Nathan G., Carroll J.M. \& Ajay K.R. 1996. Traffic flow theory.

[10]Pingfei, L., Xiaohua, Z. \& Yulong, C. 2005. The study of vehicles fuel consumption measurement method based on the carbon balance method. Light Vehicles 4:1416.

[11] Poudenx, P. 2011. The effect of transportation policies on energy consumption and greenhouse gas emission from urban passenger transportation. Transportation Research Part A Policy \& Practice 42(6): 901-909.

[12]Wei, W., Qiaojun, X. \& Tiezhu, L. 2002. Analytical method of urban traffic system energy consumption and environmental impact. Beijing: Science Press.

[13] Wright, L.A., Kemp, S. \& Williams, I. 2011. 'Carbon footprinting': towards a universally accepted definition. Carbon Management 2(1): 6172. 